\title{
The development of a new generation of methyl chloride synthesis catalyst
}

\author{
Alastair R. McInroy, ${ }^{a}$ John M. Winfield, ${ }^{a}$ Chris C. Dudman, ${ }^{b}$ Peter Jones ${ }^{b}$ \\ and David Lennon*a
}

Received 30th November 2015, Accepted 8th December 2015

DOI: $10.1039 / \mathrm{c} 5 \mathrm{fd} 00202 \mathrm{~h}$

In previous work by the authors, aspects of the surface chemistry connected with methyl chloride synthesis over an $\eta$-alumina catalyst have been examined. This communication considers a role for Group 1 metal salts to modify the catalytic performance of the well characterised $\eta$-alumina catalyst. Firstly, based on a previously postulated mechanism for the reaction of methanol on $\eta$-alumina, a mechanism for methyl chloride synthesis over the $\eta$-alumina catalyst is proposed. Secondly, the validity of the new mechanism is tested by observing how the (i) type and (ii) loading of the Group 1 metal salt may perturb methyl chloride selectivity. The outcomes of these measurements are rationalised with reference to the postulated mechanism. Overall, this study represents an example of how a proposed reaction mechanism has been used to inform and guide a catalyst development strategy for a large-scale industrial process.

\section{Introduction}

Methyl chloride is an important industrial product with a global capacity of $c a$. 900 ktonne. It is a valuable starting material in the production of higher chlorinated products, silicones, and methyl cellulose. It also has applications as a methylating agent. ${ }^{1-3}$ One method for the large scale manufacture of methyl chloride is performed via the hydrochlorination of methanol over a solid acid catalyst at elevated temperatures, eqn (1). Selectivity to methyl chloride is reduced by the reaction shown in eqn (2), where the alcohol is converted to dimethyl ether. The reactions shown in eqn (1) and (2) are both reversible, so at any given feed composition and temperature there is an equilibrium product composition. An improved methyl chloride synthesis catalyst will catalyse reaction (1) more effectively than reaction (2). A catalyst that has received considerable application is $\gamma$-alumina. ${ }^{4,5}$ Hydrochlorinations using a $\mathrm{ZnCl}_{2} / \mathrm{Al}_{2} \mathrm{O}_{3}$ catalyst also show selectivity to $\mathrm{CH}_{3} \mathrm{Cl}^{6}$ 


$$
\begin{gathered}
\mathrm{CH}_{3} \mathrm{OH}+\mathrm{HCl} \rightarrow \mathrm{CH}_{3} \mathrm{Cl}+\mathrm{H}_{2} \mathrm{O} \\
2 \mathrm{CH}_{3} \mathrm{OH} \rightarrow \mathrm{CH}_{3} \mathrm{OCH}_{3}+\mathrm{H}_{2} \mathrm{O}
\end{gathered}
$$

In 2000 ICI (UK) filed a patent demonstrating improved yields of $\mathrm{CH}_{3} \mathrm{Cl}$ when an $\eta$-alumina catalyst was doped with a Group 1 metal salt. ${ }^{7}$ In order to improve the understanding of why a doped $\eta$-alumina catalyst should convey favourable catalytic performance when applied to synthesis, we examined aspects of synthesis-related surface chemistry over an un-doped commercial grade $\eta$-alumina catalyst. ${ }^{8}$ Lundie et al. probed the surface acidity of $\eta$-alumina, identifying and characterising a distribution of active sites. Four different sites were identified: (i) strong, (ii) medium-strong, (iii) medium-weak and (iv) weak Lewis acid sites. ${ }^{9}$ That work paved the way for investigations of the adsorption of the reagents $\left(\mathrm{CH}_{3} \mathrm{OH}\right.$ and $\left.\mathrm{HCl}\right)$ on this surface. The interaction of methanol on $\eta$-alumina was probed using inelastic neutron scattering (INS) in order to determine the nature and form of the adsorption complex. ${ }^{10}$ Further studies of methanol on $\eta$-alumina using a combination of infrared spectroscopy and mass spectrometry led to the proposal of a mechanism for the formation of the dimethyl ether by-product. ${ }^{11}$ Crucially, the mechanism made a case for siteselective chemistry. Next, from studies of the adsorption of $\mathrm{HCl}$ over $\eta$-alumina, it was possible to discern how dissociative adsorption of $\mathrm{HCl}$ connected with hydroxyl group formation and hydroxyl exchange reactions. ${ }^{12}$

Progressing to the bimolecular reaction over the un-doped $\eta$-alumina catalyst, temperature-programmed reaction measurements showed how modest $\mathrm{CH}_{3} \mathrm{OCH}_{3}$ production tracks the dominant formation of methyl chloride. A coincidence of reaction profiles was attributed to both product and by-product formation processes involving a common intermediate, namely methoxy groups residing in adsorption sites of similar Lewis acidity. ${ }^{13}$ Two reviews of these investigations of $\eta$-alumina catalysts have recently appeared: Parker and Lennon have described how INS has been used to probe aspects of methyl chloride synthesis related chemistry over $\eta$-alumina, ${ }^{\mathbf{1 4}}$ and Lennon and Winfield have reviewed adsorption and reactions over $\eta$-alumina as part of a wider examination of heterogeneous catalysts used for large-scale syntheses of selected chlorohydrocarbons and fluorohydrocarbons. ${ }^{15}$

Other work carried out elsewhere has produced a series of papers describing various aspects of related chemistry and chemical engineering. Representative studies include the use of micro-reactors ${ }^{16,17}$ and the use of $\mathrm{ZnCl}_{2}$ modified zeolite and alumina based catalysts. ${ }^{18,19}$ The latter work illustrates how the addition of a zinc salt can modify the acid properties of an $\gamma$-alumina catalyst to beneficially influence product yields.

As stated above, we have previously postulated a mechanism for the reaction of methanol over an $\eta$-alumina catalyst including site selectivity. ${ }^{\mathbf{1 1}}$ Linking this postulate with catalyst characterisation studies, ${ }^{9}$ the authors deduce that it should be possible to extend this model to account for actual $\mathrm{CH}_{3} \mathrm{Cl}$ production over this substrate. Such a scheme has direct relevance to the industrial operation. Thus, in this paper, we propose a mechanism for the site-selective formation of methyl chloride over an un-doped $\eta$-alumina catalyst, Fig. 1.

Following our observations reported in the previous work on $\eta$-alumina, ${ }^{9-13}$ Fig. 1 shows methyl chloride to be formed from the reaction of adsorbed methoxy 


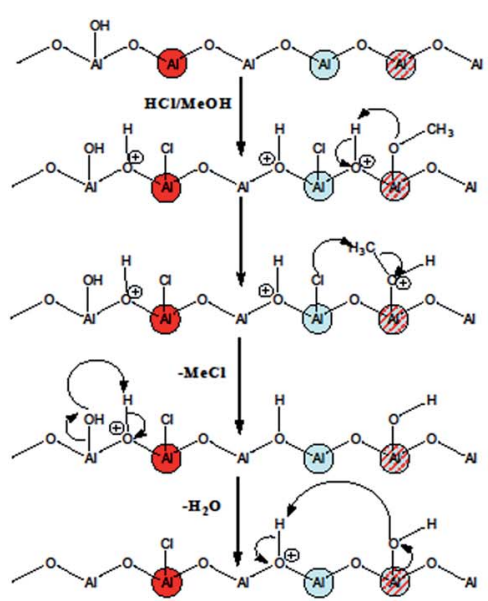

Adsorption of $\mathrm{MeOH}$ and $\mathrm{HCl}$

Formation of methyl chloride

Fig. 1 A schematic representation of the site-selective formation of methyl chloride over $\eta$-alumina. The red circles represent a strong/medium-strong Lewis acid site; the blue circles represent a medium-weak Lewis acid site; the red/blue shaded circles represent a strong/medium-strong/medium-weak Lewis acid site. The definition and form of these sites is described in ref. 9.

species and adsorbed chloride. Importantly for methyl chloride production, the chlorine species must be adsorbed on the medium-weak site, as previous temperature-programmed measurements indicate that chloride adsorbed on strong and medium-strong sites is too strongly adsorbed to engage in methyl chloride production. ${ }^{12,13}$ In contrast, the methoxy species may be adsorbed on any of the three strongest Lewis acid sites. Following deductions on the principal step for dimethyl ether production over this catalyst, ${ }^{11}$ the key step for methyl chloride formation is believed to be concerted $\mathrm{C}-\mathrm{Cl}$ formation and $\mathrm{C}-\mathrm{O}$ breakage. The mechanism is consistent with reports on the process of the reverse reaction by Yates and co-workers. ${ }^{5}$

In recognition of the earlier patent report on the benefits of Group 1 metal dopants for $\eta$-alumina, ${ }^{7}$ the validity of the site-selective chemistry indicated in Fig. 1 is tested by examining how certain additives affect catalytic performance. Given that $\mathrm{Li}$ and $\mathrm{Na}$ cations may intercalate into the alumina lattice, we have examined (i) the effect of modifying a commercial grade $\eta$-alumina with $\mathrm{K}$ and Cs salts and (ii) the effectiveness of these new materials for methyl chloride synthesis.

\section{Experimental}

\subsection{Catalyst preparation}

The $\eta$-alumina catalyst was supplied by Ineos Chlor (Ineos Chlor catalyst ref: $25867) ;^{20}$ this is the same transition alumina examined in the previous studies and that is characterised in ref. 9. The doping of the alumina catalyst with $\mathrm{K}$ and Cs salts was performed by an impregnation method. An aqueous solution of $\mathrm{CsCl}$ (Aldrich, purity 99.9\%) or $\mathrm{KCl}$ (Aldrich, purity 99.999\%) of pre-calculated concentration was added to a glass flask via a two-way adaptor and dropping funnel whilst under vacuum $\left(<10^{-2}\right.$ torr). The use of an evacuated vessel ensured 
that the salt solution entered and filled the pores of the alumina in a uniform fashion. The solution was decanted to remove excess liquid and the catalyst dried by rotary evaporation at $343 \mathrm{~K}$ for $2 \mathrm{~h}$, before final drying in an oven at $353 \mathrm{~K}$ for a further $2 \mathrm{~h}$. By varying the concentration of the original salt solution, this methodology enabled the base $\eta$-alumina catalyst to be prepared with a range of Group 1 metal salt dopant concentrations.

\subsection{Hydrochlorination reactions}

Hydrochlorination reactions were performed using a micro-reactor. A sample of the catalyst under investigation was mixed with ground Pyrex glass $(0.1 \mathrm{~g}$ catalyst, $0.9 \mathrm{~g}$ Pyrex) and placed within a $\frac{1}{4}$ " od $\mathrm{mm}$ diameter U-tube reactor that was housed inside a programmable oven (Pye 104 controlled by a Eurotherm programmable unit). Prior to reaction testing, the test facility was purged and leak tested using a nitrogen dilution stream. Methanol (Fisher Extra Dry for synthesis, $<0.01 \%$ water) was delivered to the reactor by means of a HPLC pump (Gilson) operating with a $0-5 \mathrm{ml} \mathrm{min}{ }^{-1}$ pump head. The methanol and anhydrous $\mathrm{HCl}$ (Air Products Electronic Grade $99.999 \%$ v/v purity) flows were set to $0.045 \mathrm{ml} \mathrm{min}^{-1}$

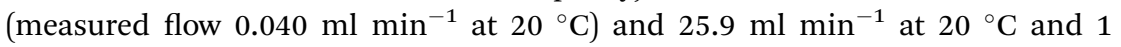
atmosphere respectively, giving a $\mathrm{HCl}$ : methanol $\mathrm{v} / \mathrm{v}$ ratio of $1.1: 1$. Gas flows were controlled using Brookes Mass Flow Controllers. Products were analysed by inline gas-liquid chromatography (HP6850, FID, 50 m CP wax 52 column $530 \mu \mathrm{m}$ diameter $2 \mu \mathrm{m}$ film thickness). Samples of the reactor exit stream were analysed at 15 min intervals using the GLC. Data were collected using a Perkin Elmer Nelson 900 interface and analysed by Perkin Elmer Turbochrom data handling software. Temperature programmed reaction (TPR) measurements commenced at $443 \mathrm{~K}$, where a temperature ramp of $10 \mathrm{~K} \mathrm{~h}^{-1}$ was applied up to $623 \mathrm{~K}$. A Grant Squirrel data logger recorded reactor temperature and mass flow controller flow rates.

\section{Results}

\subsection{Temperature profiles and activation energies: $\eta$-alumina}

Fig. 2 presents the temperature-programmed reaction profiles for methyl chloride and dimethyl ether production over the temperature range 453-613 $\mathrm{K}$ using the unmodified $\eta$-alumina catalyst. Methyl chloride production displays an almost sigmoidal profile, attaining a maximum rate at approximately $600 \mathrm{~K}$. In contrast, the $\mathrm{CH}_{3} \mathrm{OCH}_{3}$ rate reaches a maximum at $\sim 565 \mathrm{~K}$; thereafter its rate of formation diminishes quite sharply on increasing temperature. With reference to the different intensity ranges used in Fig. 2, formation of $\mathrm{CH}_{3} \mathrm{Cl}$ dwarfs the production of $\mathrm{CH}_{3} \mathrm{OCH}_{3}$; at $560 \mathrm{~K}$ and based on relative peak areas, the exit stream comprises $95.3 \% \mathrm{CH}_{3} \mathrm{Cl}$ and $4.7 \% \mathrm{CH}_{3} \mathrm{OCH}_{3}$. No other hydrocarbons or chlorohydrocarbons were detected in the analysis.

The data from Fig. 2 in the range 487-541 K can be used to generate Arrhenius plots that correspond to constrained methanol conversions of $\sim 20 \%$, Fig. 3 . Linearity for both methyl chloride and dimethyl ether production is maintained over this temperature range and yields apparent activation energies of $88.3( \pm 0.9)$ and $94.8( \pm 1.1) \mathrm{kJ} \mathrm{mol}^{-1}$ respectively, with the error representing the standard deviation from three replicate runs. The $E_{\mathrm{a}}$ value for dimethyl ether production is comparable with that reported by de Vore et al. $\left(98 \mathrm{~kJ} \mathrm{~mol}^{-1}\right)$ for its formation over 


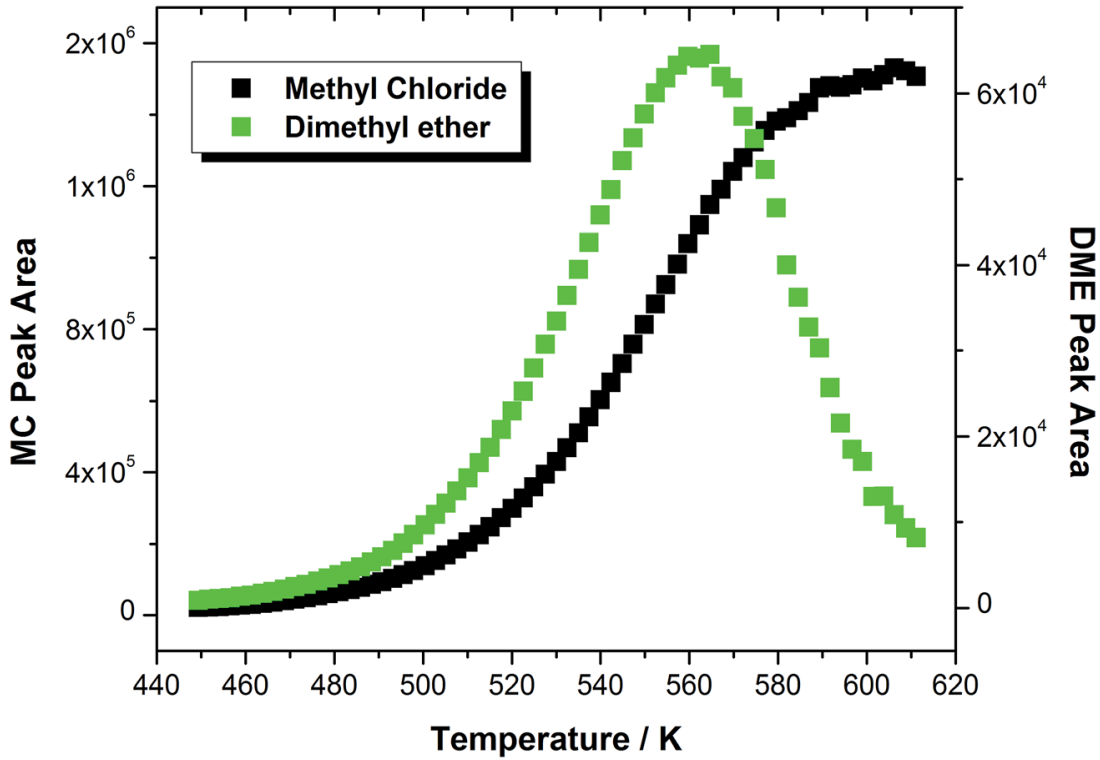

Fig. 2 Temperature-programmed reaction profile for methyl chloride (black squares, scaled according to the left hand side $Y$ axis) and dimethyl ether (green squares, scaled according to the right hand side $Y$ axis) production over the un-doped $\eta$-alumina catalyst. Note the different scales of the two $Y$ axes.

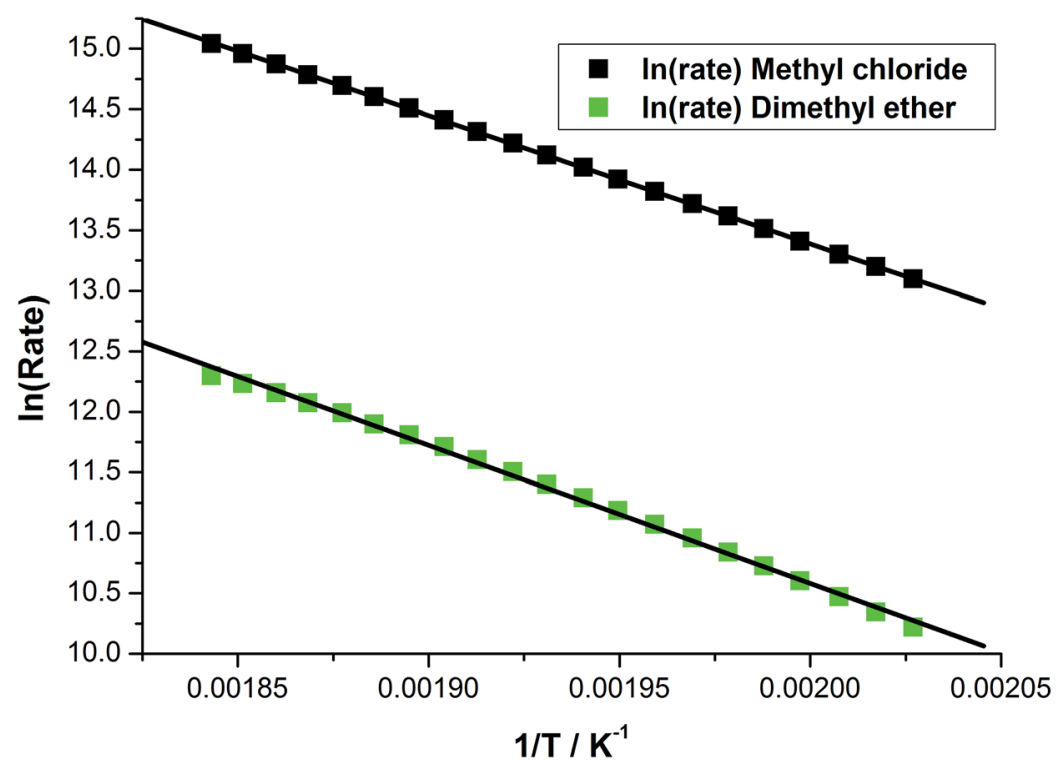

Fig. 3 Arrhenius plots for methyl chloride (black squares) and dimethyl ether (green squares) production over the un-doped $\eta$-alumina catalyst. 
a $\gamma$-alumina catalyst. ${ }^{21}$ The similarity in $E_{\text {a }}$ values for product and by-product production over the present catalyst suggests that they may be linked by a step common to both processes.

The activation energy information is helpful in understanding the different temperature profiles, Fig. 2, which are attributed to a kinetic effect. As the $E_{\mathrm{a}}$ value for $\mathrm{CH}_{3} \mathrm{OCH}_{3}$ is marginally higher than that for $\mathrm{CH}_{3} \mathrm{Cl}$, the reaction rate for the former will rise faster with increasing temperature. Thus, at elevated temperatures, the surface methoxy concentration will be depleted, thereby reducing the probability of nearby/adjacent adsorbed methoxy species; a condition necessary for the formation of dimethyl ether.

\subsection{Temperature-programmed reaction: modified $\eta$-alumina}

Fig. 4 shows how methyl chloride exit concentration varies with temperature for two doping levels of the $\mathrm{KCl}$ modifier. Fig. 5 shows the equivalent plot for the undoped $\eta$-alumina catalyst with equivalent doping levels of $\mathrm{CsCl}$. In both cases, the addition of the Group 1 metal salt leads to a drop in activity for the production of $\mathrm{CH}_{3} \mathrm{Cl}$; moreover, the greater the doping level of either salt, the greater the reduction in the rate of methyl chloride formation. For example, at the higher $\mathrm{KCl}$ loading, activity with respect to $\mathrm{CH}_{3} \mathrm{Cl}$ formation is decreased by $46.3 \%$ at $560 \mathrm{~K}$.

Fig. 6 shows how dimethyl ether production varies with respect to temperature for two doping levels of $\mathrm{KCl}$ modifier; Fig. 7 shows the equivalent plot for $\mathrm{CsCl}$. Here the effect is more dramatic than that observed for the formation of $\mathrm{CH}_{3} \mathrm{Cl}$ (Fig. 4 and 5), where a Group 1 metal salt loading of $1.0 \mathrm{mmol}_{\text {(cat) }}{ }^{-1}$ dramatically reduces the formation of $\mathrm{CH}_{3} \mathrm{OCH}_{3}$; particularly so with the Cs salt (Fig. 7).

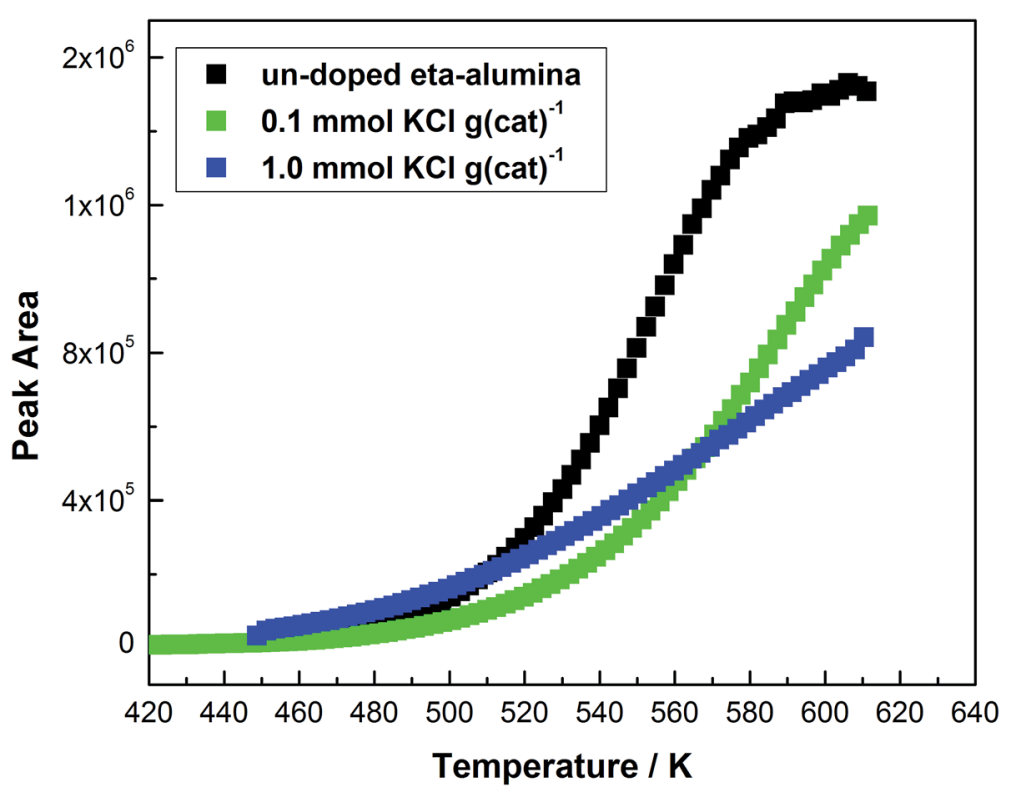

Fig. 4 Plot of methyl chloride concentration as a function of reaction temperature for (a) the un-doped $\eta$-alumina catalyst (black squares), (b) $\eta$-alumina catalyst $+0.1 \mathrm{mmol} \mathrm{KCl}$ $\mathrm{g}_{\text {(cat) }}{ }^{-1}$ (green squares), and (c) $\eta$-alumina catalyst $+1.0 \mathrm{mmol} \mathrm{KCl} \mathrm{g}_{\text {(cat) }}{ }^{-1}$ (blue squares). 


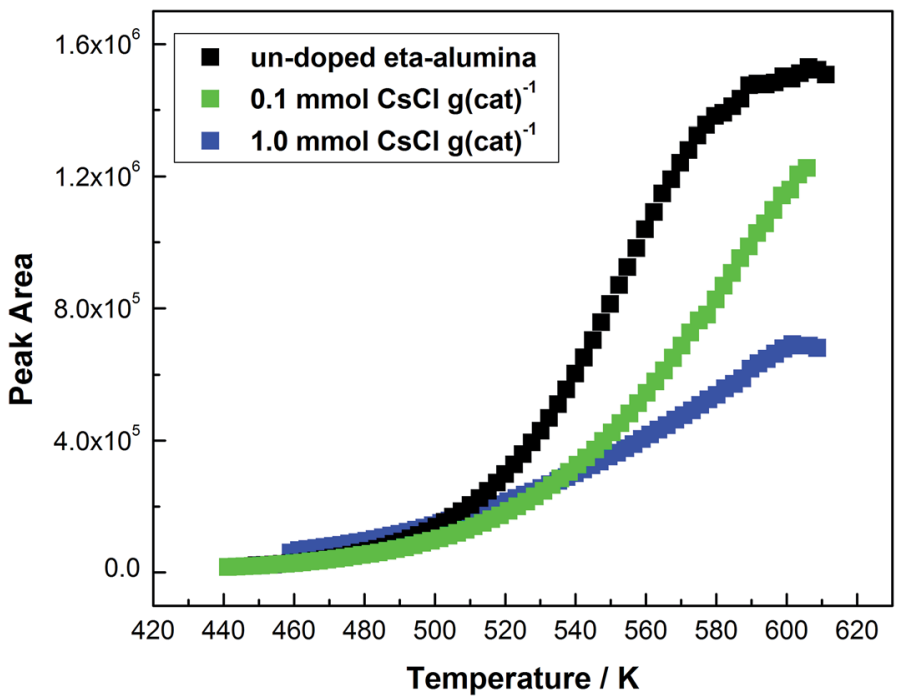

Fig. 5 Plot of methyl chloride concentration as a function of reaction temperature for (a) the un-doped $\eta$-alumina catalyst (black squares), (b) $\eta$-alumina catalyst $+0.1 \mathrm{mmol} \mathrm{CsCl}$ $\mathrm{g}_{\text {(cat) }}{ }^{-1}$ (green squares), and (c) $\eta$-alumina catalyst $+1.0 \mathrm{mmol} \mathrm{CsCl} \mathrm{g}_{\text {(cat) }}{ }^{-1}$ (blue squares).

Specifically, at $560 \mathrm{~K}$ and with reference to dimethyl ether production over the plain $\eta$-alumina catalyst, Fig. 6 shows the dimethyl ether concentration to be reduced by $92.1 \%$ at a loading of $1.0 \mathrm{mmol} \mathrm{KCl}_{\text {(cat) }}{ }^{-1}$, whilst Fig. 7 shows the

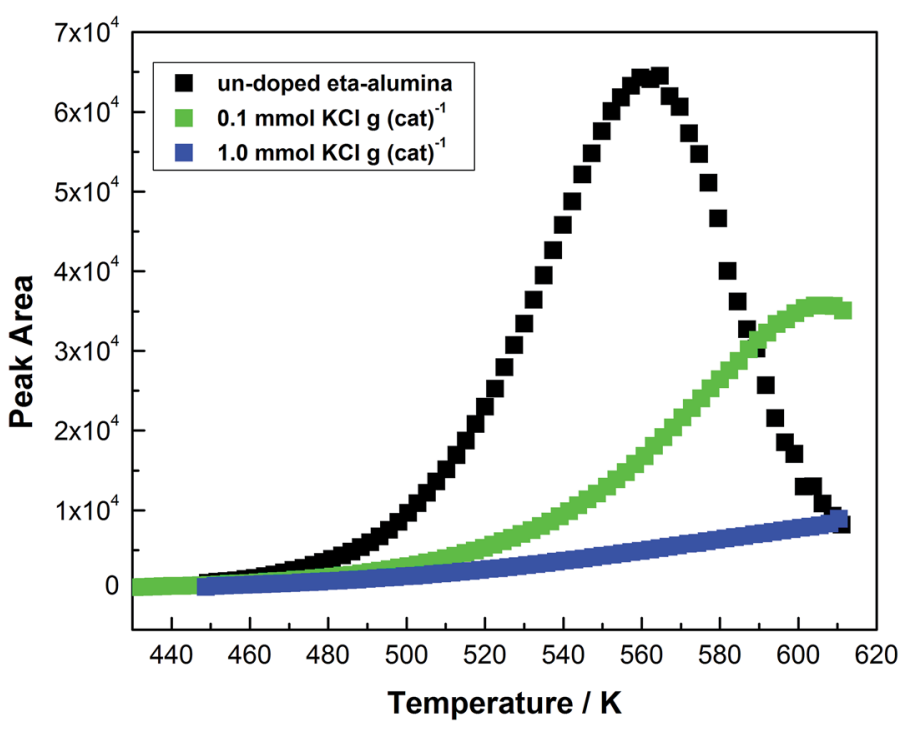

Fig. 6 Plot of dimethyl ether concentration as a function of reaction temperature for (a) the un-doped $\eta$-alumina catalyst (black squares), (b) $\eta$-alumina catalyst $+0.1 \mathrm{mmol} \mathrm{KCl}$ $\mathrm{g}_{\text {(cat) }}{ }^{-1}$ (green squares), and (c) $\eta$-alumina catalyst $+1.0 \mathrm{mmol} \mathrm{KCl} \mathrm{g}_{\text {(cat) }}{ }^{-1}$ (blue squares). 


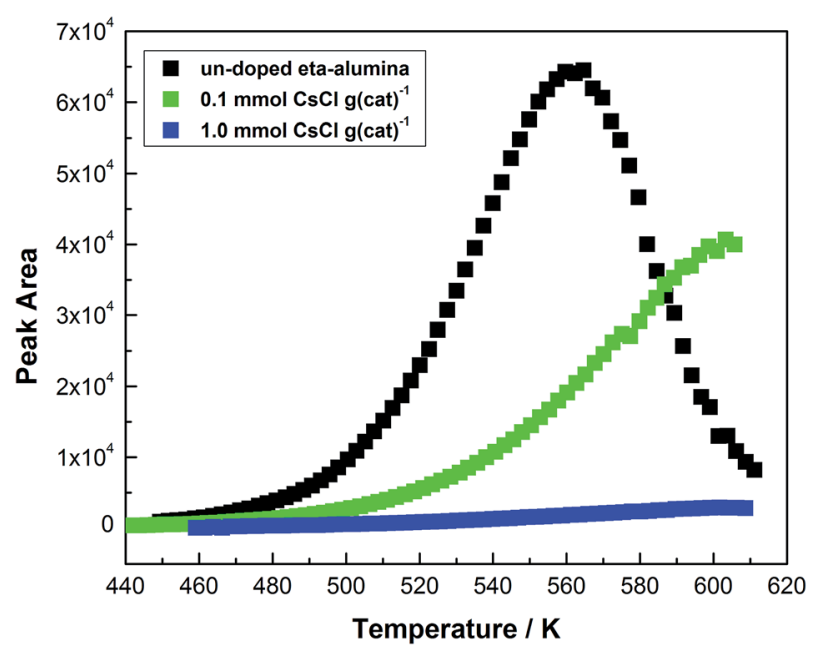

Fig. 7 Plot of dimethyl ether concentration as a function of reaction temperature for (a) the un-doped $\eta$-alumina catalyst (black squares), (b) $\eta$-alumina catalyst $+0.1 \mathrm{mmol} \mathrm{CsCl}$ $\mathrm{g}_{\text {(cat) }}{ }^{-1}$ (green squares), and (c) $\eta$-alumina catalyst $+1.0 \mathrm{mmol} \mathrm{CsCl} \mathrm{g}_{\text {(cat) }}{ }^{-1}$ (blue squares).

dimethyl ether concentration to be reduced by $97.2 \%$ at a loading of $1.0 \mathrm{mmol}$ $\mathrm{CsCl} \mathrm{g}_{\text {(cat) }}{ }^{-1}$.

Methyl chloride selectivity, $S_{(\mathrm{MC})}$, is defined according to eqn (3),

Methyl chloride selectivity $(\%)=\frac{[\text { methyl chloride }]}{[\text { methyl chloride }]+[\text { dimethyl ether }]} \times \frac{100}{1}$

Collectively, Fig. 4-7 indicate that the modified alumina catalysts exhibit an improved selectivity for methyl chloride. Although the addition of the chemical modifier reduces the concentration of product and by-product, this decline in activity is significantly more marked for dimethyl ether compared with methyl chloride production. For example, at $573 \mathrm{~K}$ the un-doped $\eta$-alumina catalyst displays a methyl chloride selectivity of $95 \%$ (Fig. 2). However, for the case of the $1.0 \mathrm{mmol} \mathrm{CsCl} \mathrm{g}_{\text {(cat) }}{ }^{-1}$ modified catalyst at the same temperature methyl chloride selectivity increases to $>99.5 \%$ (Fig. 5 and 7 ). This improvement in the selectivity of the process is highly relevant when extrapolated to the large-scale unit operation.

\subsection{Comparisons between $\mathrm{CsCl}$ and $\mathrm{KCl}$ doped $\eta$-alumina catalysts}

Whereas Fig. 4-7 indicate that Group 1 metal cation doping leads to favourable outcomes in terms of improved methyl chloride selectivity, it is important to know which dopant is more effective. Fig. 8 shows how the dimethyl ether production rate correlates with Group 1 metal salt loading, which shows both sets of samples to exhibit a significant decrease in dimethyl ether production up to loadings of $\sim 0.3 \mathrm{mmol} \mathrm{g}_{\text {(cat) }}{ }^{-1}$. Increasing Group 1 salt loadings beyond this point leads to little change in by-product concentration. Moreover, it is evident from Fig. 8 that dimethyl ether levels are noticeably higher for $\mathrm{KCl}$ doping compared with their $\mathrm{CsCl}$ counterparts. Indeed, at the highest modifier concentration studied 


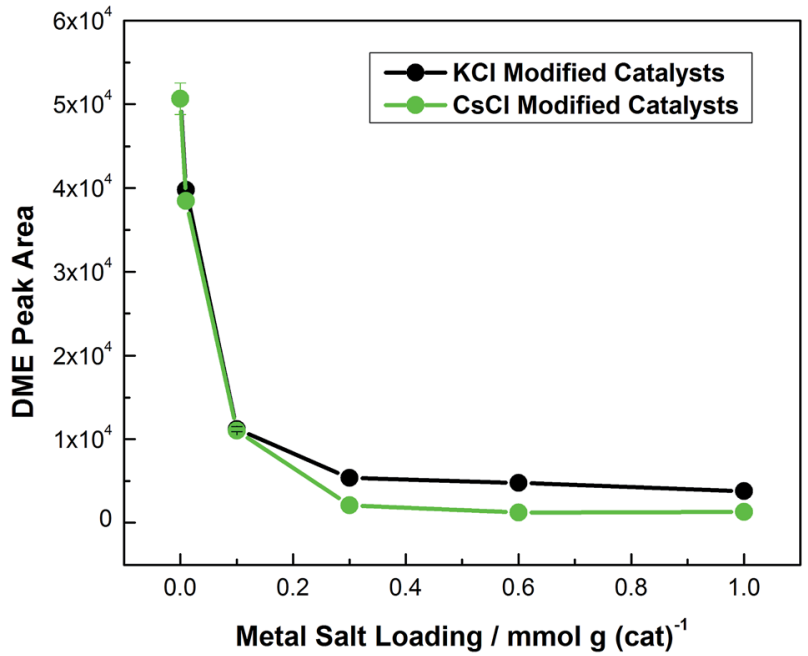

Fig. 8 Dimethyl ether production at $543 \mathrm{~K}$ as a function of alkali metal salt loading: (a) $\mathrm{KCl}$ modified $\eta$-alumina modified catalysts (black circles) and (b) $\mathrm{CsCl}$ modified $\eta$-alumina modified catalysts (green circles). The error bars represent the range observed for duplicate measurements.

(1.0 $\mathrm{mmol} \mathrm{g}_{\text {(cat) }}{ }^{-1}$ ), dimethyl ether production on the CsCl doped catalyst is one third of that produced over the $\mathrm{KCl}$ doped alumina. This action is attributed to $\mathrm{Cs}^{+}$possessing a larger ionic radius than $\mathrm{K}^{+}\left(\mathrm{Cs}^{+}=0.169 \mathrm{~nm}, \mathrm{~K}^{+}=0.133 \mathrm{~nm}\right)^{22}$ and thereby more efficiently blocking Lewis acid sites.

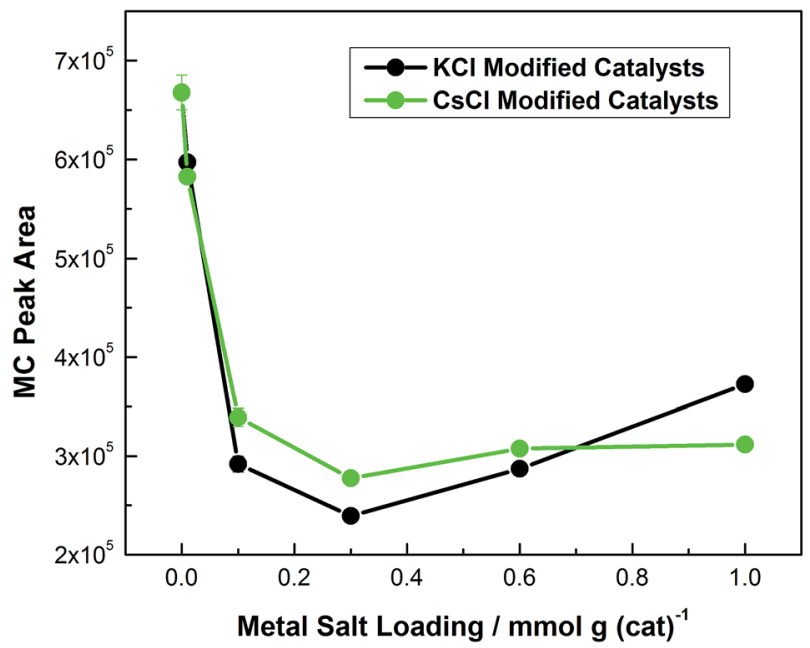

Fig. 9 Methyl chloride production at $543 \mathrm{~K}$ as a function of alkali metal salt loading: (a) $\mathrm{KCl}$ modified $\eta$-alumina modified catalysts (black circles) and (b) $\mathrm{CsCl}$ modified $\eta$-alumina modified catalysts (green circles). The error bars represent the range observed for duplicate measurements. 
The comparable trend for methyl chloride production as a function of Group 1 metal salt loading is shown in Fig. 9 and shows methyl chloride activity to be abruptly retarded up to a metal salt loading of $\sim 0.3 \mathrm{mmol} \mathrm{g}_{\text {(cat) }}{ }^{-1}$; thereafter increasing the level of the Group 1 metal salt is less influential. The reduced activity is attributed to a reduction in the surface concentration of adsorbed methoxy species due to the ion pair removing the stronger Lewis acid sites.

Fig. 9 shows that Group 1 metal salt loadings $\geq 0.3 \mathrm{mmol} \mathrm{g}_{\text {(cat) }}{ }^{-1}$ lead to approximately equal methyl chloride production rates, with the $\mathrm{KCl}$ modified alumina seemingly displaying a slightly enhanced activity at a loading of 1.0 mmol KCl g (cat) $^{-1}$. However, Fig. 8 shows that, at comparable loadings, the CsCl modified catalyst exhibits the greater reduction in dimethyl ether production. Table 1 presents the methyl chloride selectivity values for the base alumina plus the modified catalysts at high loadings (reaction temperature $=563 \mathrm{~K}$ ).

Formation of dimethyl ether during methyl chloride production is problematical in the industrial operation, as the by-product can react with chlorine elsewhere in the chloromethanes production process to produce undesirable chlorinated hydrocarbon derivatives. This means that, from the industrial perspective, enhanced methyl chloride selectivity is the primary objective. Therefore, with reference to Table 1 , the $\mathrm{CsCl}$ doped catalyst exhibits the more desirable performance: $S_{(\mathrm{MC})}=99.6 \%$. Often in heterogeneous catalysis enhanced selectivity for a specific product is achieved at the cost of activity. That principle is indeed evident here; Fig. 5 shows that doping of the base alumina catalyst with $\mathrm{CsCl}$ at a loading of $1.0 \mathrm{mmol} \mathrm{CsCl} \mathrm{g}_{\text {(cat) }}{ }^{-1}$ reduces the methyl chloride production rate at $560 \mathrm{~K}$ by $57 \%$. However, this residual activity is economically acceptable and the $5.1 \%$ improvement in methyl chloride selectivity indicated in Table 1 minimises significantly purification issues at the end of the commercial process.

\section{Discussion}

We have proposed previously that dimethyl ether production over an $\eta$-alumina catalyst occurs via a combination of chemisorbed methoxy units occupying medium-strong Lewis acid sites. ${ }^{\mathbf{1 1}}$ The mechanism for methyl chloride formation presented in Fig. 1 proposes that methyl chloride production occurs via a combination of chloride chemisorbed on medium-weak sites reacting with methoxy species bound at a combination of strong, medium-strong and mediumweak sites. Fig. 9 shows that Group 1 metal salt loadings of $\geq 0.3 \mathrm{mmol} \mathrm{g}_{\text {(cat) }}{ }^{-1}$ lead to significant decreases in $\mathrm{CH}_{3} \mathrm{Cl}$ production rates, whilst Fig. 8 indicates that comparable loadings significantly impede the $\mathrm{CH}_{3} \mathrm{OCH}_{3}$ production pathway.

Table 1 Methyl chloride selectivity values for the $\eta$-alumina catalyst and the high loading $\mathrm{KCl}$ and $\mathrm{CsCl}$ modified catalysts recorded at a reaction temperature of $563 \mathrm{~K}$

\begin{tabular}{ll}
\hline Catalyst & $\begin{array}{l}\text { Methyl chloride } \\
\text { selectivity/\% }\end{array}$ \\
\hline$\eta-\mathrm{Al}_{2} \mathrm{O}_{3}$ & 94.5 \\
$\eta-\mathrm{Al}_{2} \mathrm{O}_{3}+1.0 \mathrm{mmol} \mathrm{KCl} \mathrm{g}_{\text {(cat) }}{ }^{-1}$ & 99.0 \\
$\eta-\mathrm{Al}_{2} \mathrm{O}_{3}+1.0 \mathrm{mmol} \mathrm{CsCl} \mathrm{g}_{\text {(cat) }}^{-1}$ & 99.6
\end{tabular}


In order to understand better the site-selective chemistry connected with methyl chloride production, it is informative to review the mechanism proposed for $\mathrm{CH}_{3} \mathrm{OCH}_{3}$ production. ${ }^{11}$ One way to eliminate essentially all dimethyl ether formation would be for the Group 1 metal salt to "cap" the strong and mediumstrong Lewis acid sites. Adopting this assumption, the profile observed in Fig. 8 is interpreted to indicate that loadings of $\geq 0.3 \mathrm{mmol} \mathrm{g}_{\text {(cat) }}{ }^{-1}$ lead to the strong and medium-strong Lewis acid sites being deactivated by association with a Group 1 metal salt ion pair. Fig. 10 presents a variant of the original $\eta$-alumina/methanol mechanism (i.e. no $\mathrm{HCl}$ involvement) proposed in ref. 11 but, crucially, the area of the schematic diagram bounded by the solid black line signifies the "capping" of the strong and medium-strong Lewis acid sites. The unavailability of these sites to the incident methanol molecules prevents formation of $\mathrm{CH}_{3} \mathrm{OCH}_{3}$. This proposal is entirely consistent with the observations presented in Fig. 6-8. It is also noted that the capping of the strong Lewis acid sites will prevent the formation of surface formate species via the evolution of $\mathrm{CH}_{4}(\mathrm{~g})$ and $\mathrm{H}_{2}(\mathrm{~g})$, as previously reported for the un-doped $\eta$-alumina catalyst. ${ }^{11}$

The logic applied above for by-product formation can be readily extended to the industrially relevant formation of methyl chloride over $\eta$-alumina catalysts and is represented schematically in Fig. 11, which is a variant of Fig. 1. The shaded area of Fig. 11 indicates the inaccessibility of the strong and mediumstrong Lewis acid sites that occurs at a Group 1 metal loading of $1.0 \mathrm{mmol} \mathrm{g}_{(\mathrm{cat})}{ }^{-1}$. This leaves the medium-weak Lewis acid site as the active site: both methoxy and $\mathrm{Cl}$ chemisorb at this class of site and combine to produce $\mathrm{CH}_{3} \mathrm{Cl}$ selectively $\left(S_{(\mathrm{MC})}\right.$ $=99.6 \%$ ). This proposal is consistent with the profiles depicted in Fig. 5 and 7. Importantly, the last step shown in Fig. 11, which results in the evolution of water,

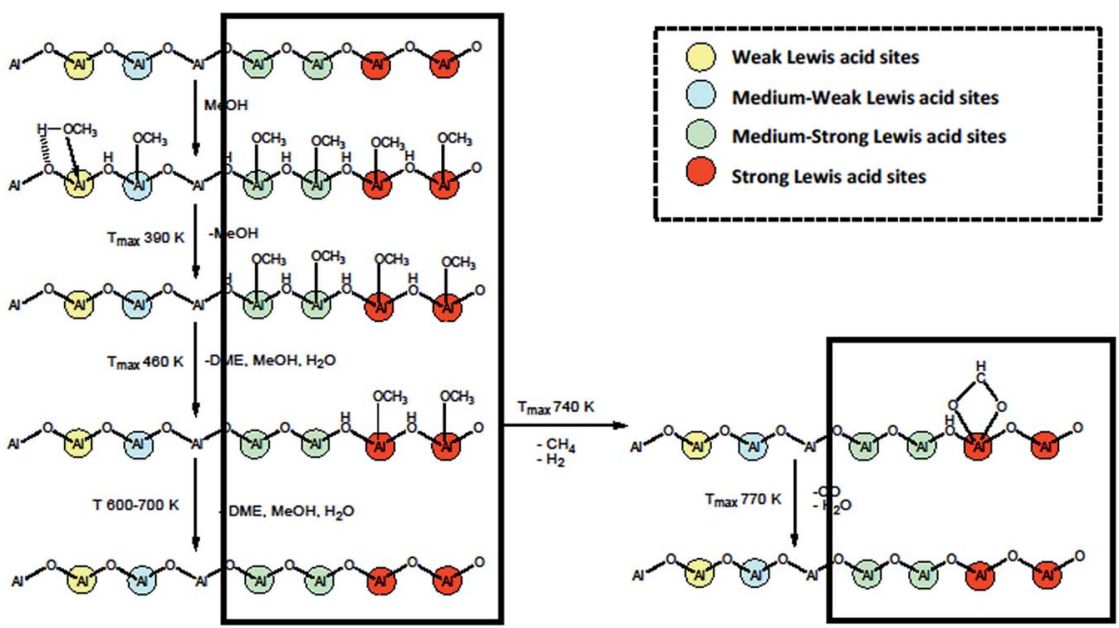

Fig. 10 Proposed methanol transformations during temperature programming of an $\eta$ alumina catalyst doped with $1.0 \mathrm{mmol} \mathrm{g}_{(\mathrm{cat})}{ }^{-1}$ of a Group 1 metal salt. The areas bounded by the solid black line represent chemistry no longer accessible due to the Group 1 metal "capping" the strong and medium-strong Lewis acid sites. This mechanism is a variation on that proposed for the reaction of methanol on $\eta$-alumina, ${ }^{11}$ that is reproduced with permission from Lundie et al., J. Phys. Chem. B, 2005, 109, 11592. Copyright 2005 American Chemical Society. 


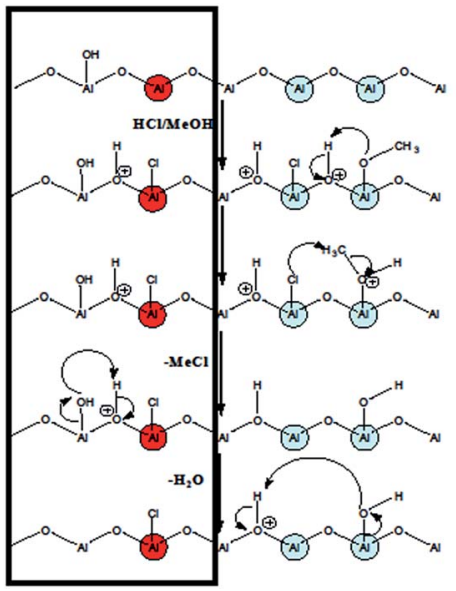

\section{Adsorption of $\mathrm{MeOH}$ and $\mathrm{HCl}$}

\section{Formation of methyl chloride}

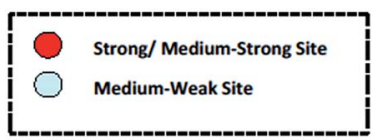

Fig. 11 Proposed reaction mechanism for methyl chloride production over an $\eta$-alumina catalyst doped with $1.0 \mathrm{mmol} \mathrm{g}_{\text {(cat) }}{ }^{-1}$ of an alkali metal salt. The area bounded by the solid black line represents chemistry no longer accessible due to the alkali metal "capping" of the strong and medium-strong Lewis acid sites.

constitutes an active site regeneration step that allows the catalytic cycle to continue; this is a pre-requisite for steady-state operation.

\section{Conclusions}

A previously reported mechanism for the reaction of methanol on an $\eta$-alumina catalyst ${ }^{11}$ has been extended and adapted to account for the hydrochlorination of methanol to produce methyl chloride. In order to evaluate the viability of the newly proposed mechanism, the $\eta$-alumina catalyst has been doped with Group 1 salts in the range $0-1.0 \mathrm{mmol} \mathrm{g}_{\text {(cat) }}{ }^{-1}$ and re-examined for methyl chloride activity. The following conclusions have been drawn.

- Temperature-programmed reaction measurements for methyl chloride and dimethyl ether over the un-doped $\eta$-alumina catalyst indicate activation energies of $88.3( \pm 0.9)$ and $94.8( \pm 1.1) \mathrm{kJ} \mathrm{mol}^{-1}$ respectively.

- Although doping of the $\eta$-alumina catalyst leads to a substantial reduction in the rate of $\mathrm{CH}_{3} \mathrm{Cl}$ formation (Fig. $5,1.0 \mathrm{mmol} \mathrm{CsCl}_{\text {(cat) }}{ }^{-1}$ reduces the production rate for $\mathrm{CH}_{3} \mathrm{Cl}$ at $560 \mathrm{~K}$ by $57 \%$ ), it significantly improves the selectivity with respect to $\mathrm{CH}_{3} \mathrm{Cl}$ (Fig. 7/Table 1: $1.0 \mathrm{mmol} \mathrm{CsCl} \mathrm{g}_{\text {(alumina) }}{ }^{-1}$ increases the methyl chloride selectivity at $563 \mathrm{~K}$ from $94.5 \%$ to $99.6 \%$ ).

- On the basis of methyl chloride activity and selectivity, modification of the $\eta$ alumina catalyst with $\mathrm{CsCl}$ at a loading of $\geq 0.3 \mathrm{mmol} \mathrm{g}_{\text {(cat) }}{ }^{-1}$ is considered to present the best catalyst formulation for sustained $\mathrm{CH}_{3} \mathrm{Cl}$ production with minimal formation of $\mathrm{CH}_{3} \mathrm{OCH}_{3}$ where kinetic control of the product composition is possible.

- With reference to the modified reaction mechanism, this improvement in product selectivity is attributed to Group 1 salt ion pairs "capping" the strong and medium-strong Lewis acid sites of the $\eta$-alumina catalyst, ${ }^{9}$ with methyl chloride production occurring solely on medium-weak Lewis acid sites. 


\section{Acknowledgements}

Ineos Chlor and the EPSRC are thanked for project support. The EPSRC are thanked for the provision of a postgraduate studentship (ARM).

\section{References}

1 K. Weissermel and H.-J. Arpe, in Industrial Organic Chemistry, VCH Wiley, 3rd edn, 1997, p. 72.

2 V. A. Makhlin and S. I. Ivanov, Kinet. Catal., 1997, 38, 865.

3 A. M. Becerra, A. E. Castro Luna, D. E. Ardissone and M. I. Ponzi, Ind. Eng. Chem. Res., 1992, 31, 1040.

4 J. E. Crowell, T. P. Beebe Jr. and J. T. Yates Jr., J. Chem. Phys., 1987, 6, 3668.

5 T. P. Beebe Jr., J. E. Crowell and J. T. Yates Jr., J. Phys. Chem., 1988, 92, 1296.

6 E. B. Svetlanov and R. M. Flid, Russ. J. Phys. Chem., 1966, 40, 1638.

7 C. J. Mitchell and P. Jones, Patent PCT Int. Appl. WO 2000076658, Imperial Chemical Industries Plc, UK, 2000.

8 In January 2001 ICI Chemicals \& Polymers Ltd. divested into Ineos Chlor Ltd.

9 D. T. Lundie, A. R. McInroy, R. Marshall, J. M. Winfield, P. Jones, C. C. Dudman, S. F. Parker, C. Mitchell and D. Lennon, J. Phys. Chem. B, 2005, 109, 11592.

10 A. R. McInroy, D. T. Lundie, J. M. Winfield, C. Dudman, P. Jones, S. F. Parker, J. W. Taylor and D. Lennon, Phys. Chem. Chem. Phys., 2005, 7, 3093.

11 A. R. McInroy, D. T. Lundie, J. M. Winfield, C. Dudman, P. Jones and D. Lennon, Langmuir, 2005, 21, 11092.

12 A. R. McInroy, D. T. Lundie, J. M. Winfield, C. C. Dudman, P. Jones, S. F. Parker and D. Lennon, Catal. Today, 2006, 114, 403.

13 A. R. McInroy, D. T. Lundie, J. M. Winfield, P. Jones, C. C. Dudman and D. Lennon, Appl. Catal., B, 2007, 70, 606.

14 S. F. Parker and D. Lennon, Acc. Chem. Res., 2014, 47, 1220.

15 J. M. Winfield and D. Lennon, New Materials for Catalytic Applications, ed. E. Kemnitz and V. Parvulescu, Elsevier, Amsterdam, 2016, ch. 7, ISBN 9780444635877.

16 S. A. Schmidt, N. Kumar, B. Zhang, K. Eränen, D. Y. Murzin and T. Salmi, Ind. Eng. Chem. Res., 2012, 51, 4545.

17 S. A. Schmidt, N. Kumar, A. Reinsdorf, K. Eränen, J. Wärnå, D. Y. Murzin and T. Salmi, Chem. Eng. Sci., 2013, 95, 232.

18 S. A. Schmidt, N. Kumar, A. Shchukarev, K. Eränen, J.-P. Mikkola, D. Y. Murzin and T. Salmi, Appl. Catal., A, 2013, 468, 120.

19 S. A. Schmidt, M. Peurla, N. Kumar, K. Eränen, D. Y. Murzin and T. Salmi, Appl. Catal., A, 2015, 490, 117.

20 In July 2015 Ineos Chlor and Solvay formed a joint venture to produce a new commercial organisation named Inovyn.

21 P. A. Clayborne, T. C. Nelson and T. C. de Vore, Appl. Catal., A, 2004, 257, 225.

22 J. G. Stark and H. G. Wallace, Chemistry Data Book, John Murray, London, 1980. 